\title{
Impact of pre-stroke dependency on outcome after endovascular therapy in acute ischemic stroke
}

\author{
Lisa Oesch ${ }^{1}$. Marcel Arnold ${ }^{1}$. Corrado Bernasconi ${ }^{1}$. Johannes Kaesmacher ${ }^{2,3} \cdot$ Urs Fischer $^{1} \cdot$ Pascal J. Mosimann $^{2}$. \\ Simon Jung ${ }^{1} \cdot$ Thomas Meinel $^{1} \cdot$ Martina Goeldlin $^{1,2} \cdot$ Mirjam Heldner $^{1} \cdot$ Bastian Volbers $^{1,4} \cdot$ Jan Gralla $^{2}$. \\ Hakan Sarikaya ${ }^{1}$
}

Received: 7 February 2020 / Revised: 13 July 2020 / Accepted: 17 August 2020 / Published online: 31 August 2020

(c) The Author(s) 2020

\begin{abstract}
Background and purpose Current demographic changes indicate that more people will be care-dependent due to increasing life expectancy. Little is known about impact of preexisting dependency on stroke outcome after endovascular treatment (EVT).

Methods We compared prospectively collected baseline and outcome data of previously dependent vs. independent stroke patients (prestroke modified Rankin Scale score of 3-5 vs. 0-2) treated with EVT. Outcome measures were favorable 3-month outcome ( $\mathrm{mRS} \leq 3$ for previously dependent and $\mathrm{mRS} \leq 2$ for independent patients, respectively), death and symptomatic intracranial hemorrhage ( $\mathrm{sICH})$.

Results Among 1247 patients, 84 (6.7\%) were dependent before stroke. They were older ( 81 vs. 72 years of age), more often female (61.9\% vs. $46 \%$ ), had a higher stroke severity at baseline (NIHSS 18 vs. 15 points), more often history of previous stroke (32.9\% vs. $9.1 \%$ ) and more vascular risk factors than independent patients. Favorable outcome and mortality were to the disadvantage of independent patients ( $26.2 \%$ vs. $44.4 \%$ and $46.4 \%$ vs. $25.5 \%$, respectively), whereas sICH was comparable in both cohorts $(4.9 \%$ vs. $5 \%$ ). However, preexisting dependency was not associated with clinical outcome and mortality after adjusting for outcome predictors (OR 1.076, 95\% CI 0.612-1.891; $p=0.799$ and OR 1.267, 95\% CI 0.758-2.119; $p=0.367$, respectively).

Conclusion Our study underscores the need for careful selection of care-dependent stroke patients when considering EVT, given a less favorable outcome observed in this cohort. Nonetheless, EVT should not systematically be withheld in patients with preexisting disability, since prior dependency does not significantly influence outcome.
\end{abstract}

Keywords Ischemic stroke $\cdot$ Endovascular treatment $\cdot$ Dependency $\cdot$ Disability $\cdot$ Outcome

\section{Background and purpose}

Jan Gralla and Hakan Sarikaya equal contribution to work.

Hakan Sarikaya

hakan.sarikaya@insel.ch

1 Department of Neurology, Bern University Hospital, Freiburgstrasse 10, 3010 Bern, Switzerland

2 Department of Diagnostic and Interventional Neuroradiology, Bern University Hospital, Freiburgstrasse 10, 3010 Bern, Switzerland

3 Department of Diagnostic, Interventional and Pediatric Radiology, Bern University Hospital, Freiburgstrasse 10, 3010 Bern, Switzerland

4 Department of Neurology, University of Erlangen-Nuremberg, Erlangen, Germany
Current demographic changes indicate that an increasing number of people will need external help in their daily life, given the rising life expectancy and incidence of care dependency among older people in Western countries [1]. As an example, an estimated 3.4 million people will be care-dependent in Germany by 2030 [2]. Concurrently, stroke has reached epidemic proportions worldwide [3] and endovascular treatment (EVT) is an approved and preferred intervention to achieve reperfusion in large cerebral artery occlusions $[4,5]$. However, little is known about the impact of preexisting dependency on stroke outcome treated with EVT as patients with modified Rankin Scale (mRS) score $\geq 2$ were excluded from latest randomized trials [5]. 
Thus, current guidelines recommend a prestroke mRS score $0-1$ for patients being considered for EVT [6, 7]. We aimed to assess the clinical outcomes in care-dependent stroke patients treated with EVT.

\section{Patients and methods}

This study was based on the Bernese stroke center database, a systematic prospective registry of consecutive patients with ischemic stroke treated at the Stroke Center of University Hospital of Berne, Switzerland. It was approved by the Local Ethics Committee Bern. For this study, we analyzed all stroke patients who underwent EVT (mechanical thrombectomy and/or intraarterial thrombolysis (IAT) with urokinase) between January 2005 and December 2016. Requests for access to the dataset from qualified researchers trained in human subject confidentiality protocols may be sent to Department of Neurology, University Hospital Berne (marcel.arnold@insel.ch). The following variables were prospectively collected as defined previously [8-10]: age, sex, prestroke mRS score, arterial hypertension, diabetes mellitus, hyperlipidemia, smoking status, history of coronary artery disease and previous stroke, antithrombotic medication at stroke onset, stroke onset-to-treatment time and stroke etiology according to the Trial of ORG 10172 in Acute Stroke Treatment (TOAST) criteria. Clinical stroke severity was assessed by a stroke neurologist at admission using the National Institutes of Health Stroke Scale (NIHSS) score [11]. Preexisting dependency was defined as prestroke mRS score 3-5, whereas patients with a prestroke mRS score 0-2 were classified as independent. We performed EVT according to our institutional guidelines as described before [12]. According to our local practice, prestroke dependency was not a strict exclusion criterion for EVT in acute ischemic stroke as we assumed that dependent patients with large vessel occlusion may also benefit from EVT. However, final treatment decision was individualized on a case-by-case basis at the discretion of the interdisciplinary team of neurologists and neuroradiologists. Patients were treated with intra-arterial urokinase, mechanical interventions, or both. Patients within $4.5 \mathrm{~h}$ after symptom onset were additionally treated with intravenous thrombolysis (IVT) [7]. All patients treated with EVT were admitted to intermediate or intensive care unit for at least $24 \mathrm{~h}$. Brain imaging with MRI or CT was systematically performed $24 \mathrm{~h}$ after intervention and in any case of clinical deterioration. Symptomatic intracranial hemorrhage (sICH) was defined according to ECASS II criteria [13]. Primary outcome measures were as follows: (1) favorable clinical outcome at 3 months (mRS score $\leq 2$ in independent patients and $\mathrm{mRS}$ score $\leq 3$ in dependent patients), (2) death within 3 months and (3) occurrence of
sICH. The endpoints were prospectively assessed during hospital stay and at 3-month outpatient visits.

\section{Statistical analysis}

We compared demographic and baseline characteristics between prestroke dependent and independent patients using Fisher exact test for dichotomous variables and Wilcoxon rank-sum test for continuous variables in univariate analyses. The independent effect of prestroke dependency on endpoints was assessed in a multivariable logistic regression model. Any variable with $\mathrm{p}<0.1$ in the univariate analysis was entered into the regression model. Age and baseline NIHSS score were entered as mandatory into the model because they have been proven to be independent predictors of clinical outcome after stroke [14]. All tests were twosided and the level of statistical significance was set to 0.05 . Statistical analyses were performed using the statistical software R (version 3.1.2; R Core Team [2014]; R: A Language and Environment for Statistical Computing; R Foundation for Statistical Computing, Vienna, Austria).

\section{Results}

A total of 1247 patients were eligible for this study. Of these, $84(6.7 \%)$ were previously dependent. Baseline characteristics of both groups are detailed in Table 1 . When compared with independent patients, those with prestroke dependency were older ( 81 vs. 72 years; $p<0.0001$ ), more often female $(61.9 \%$ vs. $46 \% ; p=0.0063)$, suffered more often from diabetes mellitus (31\% vs. $15.9 \% ; p=0.0013$ ) and arterial hypertension (79.8\% vs. $67.6 \% ; p=0.0207)$. Furthermore, dependent patients had more often a history of previous stroke $(32.9 \%$ vs. $9.1 \% ; p<0.0001)$ and pretreatment with antithrombotics $(65.1 \%$ vs. $42.6 \% ; p=0.0001)$. Baseline NIHSS score was slightly higher in dependent patients (18 vs. 15 points; $p=0.0113$ ), whereas stroke etiology and time from stroke onset to EVT did not significantly differ between both groups.

Clinical outcomes are summarized in Table 2. At 3 months, dependent patients less often reached favorable outcome (26.2\% vs. $44.4 \% ; p=0.0013)$ and had higher mortality rates $(46.4 \%$ vs. $25.5 \% ; p<0.0001)$ than independent patients, whereas sICH did not significantly differ between the groups ( $4.9 \%$ vs. $5 \% ; p=1.000)$.

For multivariable regression analyses, the following covariates were entered into the model: age, sex, dependency status, baseline NIHSS score, arterial hypertension, diabetes mellitus, pre-stroke use of antithrombotics, and history of previous stroke. After adjusting for these covariates, dependency status was no more associated with favorable 
Table 1 Baseline characteristics according to prestroke dependency status in patients treated with endovascular treatment

\begin{tabular}{llcc}
\hline & Prestroke dependent (mRS 3-5) & $\begin{array}{l}\text { Prestroke inde- } \\
\text { pendent (mRS } \\
0-2)\end{array}$ & $\begin{array}{c}\text { Dependent vs } \\
\text { independent }\end{array}$ \\
& Value & Value & $p$ value \\
\hline Age, y, median (IQR) & $81(73.75-85)$ & $72(60-79)$ & $<0.0001$ \\
Female sex (\%) & $52 / 84(61.9)$ & $535 / 1163(46.0)$ & 0.0063 \\
Baseline NIHSS score, median (IQR) & $18(11-21)$ & $15(10-19)$ & 0.0113 \\
Arterial hypertension (\%) & $67 / 84(79.8)$ & $784 / 1160(67.6)$ & 0.0207 \\
Diabetes mellitus (\%) & $26 / 84(31.0)$ & $185 / 1161(15.9)$ & 0.0013 \\
Hyperlipidemia (\%) & $43 / 82(52.4)$ & $661 / 1147(57.6)$ & 0.3583 \\
Smoking (\%) & $9 / 64(14.1)$ & $237 / 1063(22.3)$ & 0.1595 \\
Coronary Artery Disease (\%) & $14 / 82(17.1)$ & $217 / 1154(18.8)$ & 0.771 \\
History of previous stroke (\%) & $27 / 82(32.9)$ & $105 / 1158(9.1)$ & $<0.0001$ \\
Pre-stroke use of antithrombotics (\%) & $54 / 83(65.1)$ & $491 / 1153(42.6)$ & 0.0001 \\
OTT [min], median (IQR) & $276.5(199.5-352.25)$ & $272(209-363)$ & 0.5836 \\
Cause of stroke & & & 0.1325 \\
Large artery atherosclerosis (\%) & $5 / 84(6)$ & $170 / 1163(14.6)$ & \\
Cardiac embolism (\%) & $41 / 84(48.8)$ & $485 / 1163(41.7)$ & \\
Small artery disease (\%) & $0 / 84(0)$ & $1 / 1163(0.1)$ & \\
Other determined cause (\%) & $3 / 84(3.6)$ & $69 / 1163(5.9)$ & \\
Undetermined cause (\%) & $35 / 84(41.7)$ & $438 / 1163(37.7)$ & \\
\hline
\end{tabular}

IQR indicates Interquartile Range; NIHSS National Institutes of Health Stroke Scale; OTT onset to treatment time

Table 2 Outcome according to prestroke dependency status in patients treated with endovascular treatment

\begin{tabular}{lllll}
\hline & \multicolumn{2}{l}{ Outcome measures } & & \\
\cline { 2 - 5 } & $\begin{array}{l}\text { Prestroke dependent } \\
{[n / N(\%)]}\end{array}$ & $\begin{array}{l}\text { Prestroke independent } \\
{[n / N(\%)]}\end{array}$ & $\begin{array}{l}p \text { value } \\
\text { Unadjusted [OR, 95\% CI] }\end{array}$ & $\begin{array}{l}p \text { value } \\
\text { Adjusted* }[\mathrm{OR}, 95 \% \mathrm{CI}]\end{array}$ \\
\hline Death at 3 months & $39 / 84(46.4)$ & $297 / 1163(25.5)$ & $<0.0001$ & $0.367 *$ \\
& & & {$[2.525(1.567-4.049)]$} & {$[1.267(0.758-2.119)]$} \\
Good outcome at 3 months** & $22 / 84(26.2)$ & $516 / 1163(44.4)$ & 0.0013 & $0.799 *$ \\
& & & {$[0.445(0.257-0.746)]$} & {$[1.076(0.612-1.891)]$} \\
sICH & $4 / 81(4.9)$ & $57 / 1133(5)$ & 1 & 0.833 \\
& & & {$[0.980(0.252-2.755)]$} & {$[1.124(0.380-3.324)]$} \\
\hline
\end{tabular}

OR indicates odds ratio; $C I$ confidence interval; $s I C H$ symptomatic intracranial hemorrhage; NIHSS National Institutes of Health Stroke Scale

*Adjusted for age, sex, dependency status, baseline NIHSS score, arterial hypertension, diabetes mellitus, pre-stroke use of antithrombotics, and history of previous stroke ${ }^{* *}$ Good outcome was defined as 3-month modified Rankin scale (mRS) score 0-3 for previously care-dependent patients and mRS score $0-2$ for previously independent patients

outcome (odds ratio [OR], 1.076; 95\% confidence interval [CI], 0.612-1.891; $p=0.799)$, mortality (OR, 1.267; 95\% CI $0.758-2.119 ; p=0.367)$, or $\mathrm{sICH}$ (OR, $1.12495 \%$ CI $0.380-3.324 ; p=0.833)$.

\section{Discussion}

This study examined the impact of pre-existing dependency on stroke outcome after EVT and revealed some important findings. First, the rate of care-dependent patients undergoing EVT in our cohort was similar as compared with a large multicenter study investigating intravenous thrombolysis (IVT) in 7430 stroke patients (6.7\% vs. 6.6\%) [15]. This rate is also similar to the proportions reported in large trials of SITS-EAST and SITS-MOST, meaning that the willingness to thrombolyse care-dependent stroke patients has not increased [16, 17]. Thus, care-dependent patients constitute still a minor but existent subgroup for stroke physicians in their daily clinical work [18]. However, their proportion may markedly increase in near future with respect to the recent demographic changes, which again underlines 
the role of this study [19]. In line with this, the proportion of care-dependent stroke patients undergoing treatment with EVT was higher (11\%) according to a recently published multicenter study [20]. Second, care-dependent patients in our cohort had a higher burden of vascular risk factors that are associated with poor stroke outcome: they were older, had more severe stroke and more cardiovascular risk factors (e.g., arterial hypertension and diabetes mellitus) and up to one-third had already suffered from stroke before as compared to independent patients. These findings are in line with other studies reporting unbalanced baseline characteristics to the disadvantage of care-dependent stroke patients $[15,21$, 22]. Third, dependent patients had less often a favorable outcome and a higher mortality risk as compared to independent patients $(26.2 \%$ vs $44.4 \%$ and $46.4 \%$ vs. $25.5 \%$, respectively). However, dependency status was not associated with clinical outcomes after adjusting for potential confounders. Thus, the unfavorable outcome in dependent patients is probably related to the differences at baseline (e.g., older age and stroke severity) and higher disease burden as mentioned above and not to the dependency status itself [23, 24]. It has been shown that the likelihood of favorable stroke outcome after EVT linearly decreases with age [25-27]. Furthermore, older patients with pre-stroke dependency may have a higher susceptibility for medical complications such as pneumonia and medical care may be more often withdrawn after thrombolysis according to patient's preferences [15, 28]. Of note, the outcome of pre-dependent stroke patients without thrombolysis is worse in any case as untreated stroke patients with pre-existing dependency were reported to have a 2.2-fold higher mortality risk than independent patients [29-31]. Therefore, EVT should not be systematically withdrawn in care-dependent patients. Our results suggest a careful selection of care-dependent patients for EVT and an accurate adjusting of patient and family expectations with respect to the outcomes. Leker and colleagues reported that stroke patients with pre-existing disability treated with EVT may have a 4.4-fold increased risk for poor clinical outcome $(\mathrm{mRS} \geq 4)$. However, the study size was rather small (23 dependent vs. 108 independent patients) and definition of outcomes different than in our study [32]. Goldhoorn and colleagues analyzed data of 157 dependent stroke patients from MR CLEAN registry and reported results that were very similar to our study [20]. Favorable outcome was seen in $27 \%$ of prestroke-dependent patients, compared with $42 \%$ of prestroke-independent patients $(p<0.05)$ [20]. After adjustment, prestroke dependency was not associated with less-favorable outcome, whereas intracranial bleeding risk was similar in both groups. [20] However, the authors defined 3-month favorable outcome as mRS 0-2 or not worsening of the mRS score [20]. In comparison, we routinely used a dichotomized classification of prestroke mRS either as 0-2 (independent) or 3-5 (care-dependent) rather than using a continuous numerical score for prestroke mRS. Thus, prestroke care-dependent patients with 3 -month mRS 4 or 5 were not able to achieve favorable outcome (defined as $m R S \leq 3$ ) in our study. We therefore assume that the rate of care-dependent stroke patients achieving favorable outcome after EVT may have been even higher in our study by applying the same outcome definition as reported from MR CLEAN trial [20]. Instead, we used a predefined sliding dichotomy analysis for favorable outcome (mRS 0-2 for independent patients vs. mRS $0-3$ for care-dependent patients) as recommended for outcome assessment in unbalanced cohorts with varying prognostic factors [33]. Of note, literature on EVT in care-dependent stroke patients is sparse as care-dependent patients have been excluded from randomized controlled studies yet [34-37]. Karlinski and colleagues investigated 7250 stroke patients treated with IVT and reported that patients with prestroke dependency $(\mathrm{mRS} \geq 3)$ were less likely to achieve favorable outcome at 3 months despite IVT ( $\mathrm{OR}_{\text {adjusted }} 0.59$; 95\% CI 0.34-1.01; $p=0.055$ ) [22]. In addition, dependency status was independently associated with mortality in both large IVT trials $[15,22]$. In view of these results, one may speculate whether care-dependent patients with acute stroke might benefit more from EVT than IVT, but a firm conclusion is not possible due to lack of comparative studies. This is especially of relevance as dependent patients had a higher stroke severity (as measured by baseline NIHSS score) in our study as compared to the two abovementioned IVT trials, while EVT has been shown to be more effective treatment of severe stroke due to large vessel occlusion than IVT $[5,15,22,38]$. Another interesting finding of our study is that the risk of sICH in care-dependent patients was not increased as compared to the counterpart (4.9\% vs. 5\%) although bleeding predictors such as older age, higher stroke severity, history of previous stroke and increased use of antithrombotics at stroke onset were distributed to the disadvantage of dependent patients [27, 39-43]. The risk of sICH in our cohort was also comparable to the bleeding risk in care-dependent patients treated with IVT (4.8\%) and lower than in MR CLEAN registry $(8 \%)[15,44]$. Thus, the unfavorable outcomes in dependent patients are not related to an excess of intracranial bleeding complications and EVT seems to be safe in care-dependent patients.

The main strength of this study is the high data quality due to systematic and prospective data collection at baseline and 3 months by certified neurologists. Assessment of the data, therefore, is unlikely to have been influenced by the current research question. Nevertheless, we are aware of several limitations.

First, this is a non-randomized observational study including a relatively small sample size of dependent stroke patients with unbalanced baseline characteristics in both cohorts. Second, a selection and treatment bias is likely in 
view of the observational study design and may not be completely removed through multivariate model. Thus, we urge to a cautious interpretation of our findings. Third, we were not able to assess the exact causes of pre-stroke dependency and the exact mRS score in dependent patients. Fourth, data were collected over 10 years during which incremental steps in stroke treatment were implemented. Especially recanalization techniques and acute stroke care treatment like stroke unit care and early rehabilitation might influence outcome in stroke patients. Nevertheless, EVT has a long tradition in our center and has been systematically performed. Finally, the rating of prestroke mRS might be challenging due to a high degree of interobserver variability $[45,46]$.

\section{Conclusion}

This study revealed unfavorable outcomes in care-dependent stroke patients after EVT and suggests a careful patient selection for EVT. However, prestroke dependency should not be a reason to withhold EVT in these patients as outcome was rather related to unfavorable baseline differences in dependent patients (e.g., older age, higher stroke severity, history of previous stroke) and was not determined by the dependency status itself. Furthermore, EVT seems to be safe in care-dependent stroke patients with respect to similar risk of sICH in both cohorts. A well-powered randomizedcontrolled trial would be ideal to assess the safety and efficacy of EVT in care-dependent patients and to identify the patients who benefit most from EVT.

Funding Open access funding provided by University of Bern. This study was supported by the Swiss Heart Foundation.

Data availability Requests for access to the dataset from qualified researchers trained in human subject confidentiality protocols may be sent to Department of Neurology, University Hospital Berne (marcel. arnold@insel.ch).

Code availability R (version 3.1.2; R Core Team [2014]; R: A Language and Environment for Statistical Computing; R Foundation for Statistical Computing, Vienna, Austria).

\section{Compliance with ethical standards}

Conflicts of interest Unrelated: Professor Gralla is a global PI of STAR, CEC member of the PROMISE study (Penumbra) PI for the SWIFT DIRECT study (Medtronic), Consultancy; and receives SNSF grants for magnetic resonance imaging in stroke. Professor Fischer is a global PI for the SWIFT DIRECT study (Medtronic) and receives research grants from Swiss National Science Foundation (SNSF). Dr. Mosimann receives research grants from Swiss National Science Foundation (SNSF) to study new therapeutic options for cerebral aneurysms and cerebral vasospasm. Mr. Kaesmacher received travel support by Stryker and Pfizer. Dr. Volbers reports personal fees from Pfizer AG/ Bristol-Myers Squibb SA, personal fees from Bayer AG, and grants from Institutional grant (Inselspital) outside the submitted work. All other authors have nothing to disclose.

Ethical approval All procedures performed in studies involving human participants were in accordance with the ethical standards of the institutional and/or national research committee and with the 1964 Helsinki declaration and its later amendments or comparable ethical standards.

Informed consent Informed consent was obtained from all individual participants included in the study.

Open Access This article is licensed under a Creative Commons Attribution 4.0 International License, which permits use, sharing, adaptation, distribution and reproduction in any medium or format, as long as you give appropriate credit to the original author(s) and the source, provide a link to the Creative Commons licence, and indicate if changes were made. The images or other third party material in this article are included in the article's Creative Commons licence, unless indicated otherwise in a credit line to the material. If material is not included in the article's Creative Commons licence and your intended use is not permitted by statutory regulation or exceeds the permitted use, you will need to obtain permission directly from the copyright holder. To view a copy of this licence, visit http://creativecommons.org/licenses/by/4.0/.

\section{References}

1. Schnitzer S, Bluher S, Teti A, Schaeffner E, Ebert N, Martus P, Suhr R, Kuhlmey A (2019) Risk profiles for care dependency: cross-sectional findings of a population-based cohort study in Germany. J Aging Health. https://doi.org/10.1177/0898264318 822364

2. Pflegestatistik 2015. (2017) https://www.destatis.de/DE/Publi kationen/Thematisch/Gesundheit/Pflege/LaenderPflegebeduerf tige5224002159004.pdf; jsessionid=ECEDDF1E11 A6CC2 F4411A579CBE9F9CD.InternetLive2?_blob=publicationFile. Accessed 03 Sep 2019

3. GBDLRoS, Feigin VL, Nguyen G, Cercy K, Johnson CO, Alam T, Parmar PG, Abajobir AA, Abate KH, Abd-Allah F, Abejie AN, Abyu GY, Ademi Z, Agarwal G, Ahmed MB, Akinyemi RO, AlRaddadi R, Aminde LN, Amlie-Lefond C, Ansari H, Asayesh H, Asgedom SW, Atey TM, Ayele HT, Banach M, Banerjee A, Barac A, Barker-Collo SL, Bärnighausen T, Barregard L, Basu S, Bedi N, Behzadifar M, Béjot Y, Bennett DA, Bensenor IM, Berhe DF, Boneya DJ, Brainin M, Campos-Nonato IR, Caso V, Castañeda-Orjuela CA, Rivas JC, Catalá-López F, Christensen H, Criqui MH, Damasceno A, Dandona L, Dandona R, Davletov K, de Courten B, deVeber G, Dokova K, Edessa D, Endres M, Faraon EJA, Farvid MS, Fischer F, Foreman K, Forouzanfar MH, Gall SL, Gebrehiwot TT, Geleijnse JM, Gillum RF, Giroud M, Goulart AC, Gupta R, Gupta R, Hachinski V, Hamadeh RR, Hankey GJ, Hareri HA, Havmoeller R, Hay SI, Hegazy MI, Hibstu DT, James SL, Jeemon P, John D, Jonas JB, Jóźwiak J, Kalani R, Kandel A, Kasaeian A, Kengne AP, Khader YS, Khan AR, Khang Y-H, Khubchandani J, Kim D, Kim YJ, Kivimaki M, Kokubo Y, Kolte D, Kopec JA, Kosen S, Kravchenko M, Krishnamurthi R, Kumar GA, Lafranconi A, Lavados PM, Legesse Y, Li Y, Liang X, Lo WD, Lorkowski S, Lotufo PA, Loy CT, Mackay MT, Abd El Razek HM, Mahdavi M, Majeed A, Malekzadeh R, Malta DC, Mamun AA, Mantovani LG, Martins SCO, Mate KK, Mazidi M, Mehata S, Meier T, Melaku YA, Mendoza W, Mensah GA, Meretoja A, Mezgebe HB, Miazgowski T, Miller TR, Ibrahim NM, Mohammed S, Mokdad AH, Moosazadeh M, Moran AE, Musa KI, Negoi RI, Nguyen M, Nguyen QL, Nguyen TH, Tran 
TT, Nguyen TT, Anggraini Ningrum DN, Norrving B, Noubiap JJ, O'DonnellMJ Olagunju AT, Onuma OK, Owolabi MO, Parsaeian M, Patton GC, Piradov M, Pletcher MA, Pourmalek F, Prakash V, Qorbani M, Rahman M, Rahman MA, Rai RK, Ranta A, Rawaf D, Rawaf S, Renzaho AMN, Robinson SR, Sahathevan R, Sahebkar A, Salomon JA, Santalucia P, Santos IS, Sartorius B, Schutte AE, Sepanlou SG, Shafieesabet A, Shaikh MA, Shamsizadeh M, Sheth KN, Sisay M, Shin M-J, Shiue I, Silva DAS, Sobngwi E, Soljak M, Sorensen RJD, Sposato LA, Stranges S, Suliankatchi RA, Tabarés-Seisdedos R, Tanne D, Nguyen CT, Thakur JS, Thrift AG, Tirschwell DL, Topor-Madry R, Tran BX, Nguyen LT, Truelsen T, Tsilimparis N, Tyrovolas S, Ukwaja KN, Uthman OA, Varakin Y, Vasankari T, Venketasubramanian N, Vlassov VV, Wang W, Werdecker A, Wolfe CDA, Xu G, Yano Y, Yonemoto N, Yu C, Zaidi Z, El Sayed Zaki M, Zhou M, Ziaeian B, Zipkin B, Vos T, Naghavi M, Murray CJL, Roth GA (2018) Global, regional, and country-specific lifetime risks of stroke, 1990 and 2016. N Engl J Med 379(25):2429-2437. https://doi. org/10.1056/NEJMoa1804492

4. Catanese L, Tarsia J, Fisher M (2017) Acute Ischemic stroke therapy overview. Circ Res 120(3):541-558. https://doi.org/10.1161/ CIRCRESAHA.116.309278

5. Goyal M, Menon BK, van Zwam WH, Dippel DW, Mitchell PJ, Demchuk AM, Davalos A, Majoie CB, van der Lugt A, de Miquel MA, Donnan GA, Roos YB, Bonafe A, Jahan R, Diener HC, van den Berg LA, Levy EI, Berkhemer OA, Pereira VM, Rempel J, Millan M, Davis SM, Roy D, Thornton J, Roman LS, Ribo M, Beumer D, Stouch B, Brown S, Campbell BC, van Oostenbrugge RJ, Saver JL, Hill MD, Jovin TG, Collaborators H (2016) Endovascular thrombectomy after large-vessel ischaemic stroke: a meta-analysis of individual patient data from five randomised trials. Lancet 387(10029):1723-1731. https://doi.org/10.1016/S0140 -6736(16)00163-X

6. Powers WJ, Derdeyn CP, Biller J, Coffey CS, Hoh BL, Jauch EC, Johnston KC, Johnston SC, Khalessi AA, Kidwell CS, Meschia JF, Ovbiagele B, Yavagal DR, American Heart Association Stroke C (2015) 2015 American heart association/American stroke association focused update of the 2013 guidelines for the early management of patients with acute ischemic stroke regarding endovascular treatment: a guideline for healthcare professionals from the American heart association/American stroke association. Stroke 46(10):3020-3035. https://doi.org/10.1161/STR.0000000000 000074

7. Powers WJ, Rabinstein AA, Ackerson T, Adeoye OM, Bambakidis NC, Becker K, Biller J, Brown M, Demaerschalk BM, Hoh B, Jauch EC, Kidwell CS, Leslie-Mazwi TM, Ovbiagele B, Scott PA, Sheth KN, Southerland AM, Summers DV, Tirschwell DL (2018) 2018 Guidelines for the early management of patients with acute ischemic stroke: a guideline for healthcare professionals from the American heart association/American stroke association. Stroke 49(3):e46-e99. https://doi.org/10.1161/STR.0000000000000158

8. Adams HP Jr, Bendixen BH, Kappelle LJ, Biller J, Love BB, Gordon DL, Marsh EE 3rd (1993) Classification of subtype of acute ischemic stroke. Definitions for use in a multicenter clinical trial. TOAST. Trial of Org 10172 in acute stroke treatment. Stroke 24(1):35-41

9. Nedeltchev K, Fischer U, Arnold M, Ballinari P, Haefeli T, Kappeler L, Brekenfeld C, Remonda L, Schroth G, Mattle HP (2006) Long-term effect of intra-arterial thrombolysis in stroke. Stroke 37(12):3002-3007. https://doi.org/10.1161/01.STR.0000249417 .24085 .80

10. van Swieten JC, Koudstaal PJ, Visser MC, Schouten HJ, van Gijn J (1988) Interobserver agreement for the assessment of handicap in stroke patients. Stroke 19(5):604-607

11. Brott T, Adams HP Jr, Olinger CP, Marler JR, Barsan WG, Biller J, Spilker J, Holleran R, Eberle R, Hertzberg V et al (1989)
Measurements of acute cerebral infarction: a clinical examination scale. Stroke 20(7):864-870

12. Broeg-Morvay A, Mordasini P, Bernasconi C, Buhlmann M, Pult F, Arnold M, Schroth G, Jung S, Mattle HP, Gralla J, Fischer U (2016) Direct mechanical intervention versus combined intravenous and mechanical intervention in large artery anterior circulation stroke: a matched-pairs analysis. Stroke 47(4):1037-1044. https://doi.org/10.1161/STROKEAHA.115.011134

13. Hacke W, Kaste M, Fieschi C, von Kummer R, Davalos A, Meier D, Larrue V, Bluhmki E, Davis S, Donnan G, Schneider D, DiezTejedor E, Trouillas P (1998) Randomised double-blind placebocontrolled trial of thrombolytic therapy with intravenous alteplase in acute ischaemic stroke (ECASS II). Lancet 352(9136):12451251. https://doi.org/10.1016/S0140-6736(98)08020-9

14. Brown DL, Johnston KC, Wagner DP, Haley EC (2004) Predicting major neurological improvement with intravenous recombinant tissue plasminogen activator treatment of stroke. Stroke 35(1):147-150. https://doi.org/10.1161/01.STR.0000105396 .93273 .72

15. Gensicke H, Strbian D, Zinkstok SM, Scheitz JF, Bill O, Hametner C, Moulin S, Zini A, Kagi G, Pezzini A, Padjen V, Bejot Y, Corbiere S, Zonneveld TP, Seiffge DJ, Roos YB, Traenka C, Putaala J, Peters N, Bonati LH, Curtze S, Erdur H, Sibolt G, Koch P, Vandelli L, Ringleb P, Leys D, Cordonnier C, Michel P, Nolte CH, Lyrer PA, Tatlisumak T, Nederkoorn PJ, Engelter ST, Thrombolysis in Stroke Patients C (2016) Intravenous thrombolysis in patients dependent on the daily help of others before stroke. Stroke 47(2):450-456. https://doi.org/10.1161/STROKEAHA.115.011674

16. Karlinski M, Kobayashi A, Mikulik R, Sanak D, Wahlgren N, Czlonkowska A (2012) Intravenous Alteplase in Ischemic Stroke Patients not Fully Adhering to the Current Drug License in Central and Eastern Europe. International Journal of Stroke 7(8):615622. https://doi.org/10.1111/j.1747-4949.2011.00733.x

17. Wahlgren N, Ahmed N, Dávalos A, Ford GA, Grond M, Hacke W, Hennerici MG, Kaste M, Kuelkens S, Larrue V, Lees KR, Roine RO, Soinne L, Toni D, Vanhooren G (2007) Thrombolysis with alteplase for acute ischaemic stroke in the Safe Implementation of Thrombolysis in Stroke-Monitoring Study (SITS-MOST): an observational study. The Lancet 369(9558):275-282. https://doi. org/10.1016/S0140-6736(07)60149-4

18. Gumbinger C, Reuter B, Hacke W, Sauer T, Bruder I, Diehm C, Wiethölter H, Schoser K, Daffertshofer M, Neumaier S, Drewitz E, Rode S, Kern R, Hennerici MG, Stock C, Ringleb P (2016) Restriction of therapy mainly explains lower thrombolysis rates in reduced stroke service levels. Neurology 86(21):1975. https:// doi.org/10.1212/WNL.0000000000002695

19. Matthews FE, Arthur A, Barnes LE, Bond J, Jagger C, Robinson L, Brayne C (2013) A two-decade comparison of prevalence of dementia in individuals aged 65 years and older from three geographical areas of England: results of the Cognitive Function and Ageing Study I and II. The Lancet 382(9902):1405-1412. https ://doi.org/10.1016/S0140-6736(13)61570-6

20. Goldhoorn RB, Verhagen M, Dippel DWJ, van der Lugt A, Lingsma HF, Roos Y, Majoie C, Vos JA, Boiten J, van Zwam WH, van Oostenbrugge RJ, van den Wijngaard I, Investigators MCR (2018) Safety and outcome of endovascular treatment in prestroke-dependent patients. Stroke 49(10):2406-2414. https:// doi.org/10.1161/STROKEAHA.118.022352

21. Foell RB, Silver B, Merino JG, Wong EH, Demaerschalk BM, Poncha F, Tamayo A, Hachinski V (2003) Effects of thrombolysis for acute stroke in patients with pre-existing disability. CMAJ 169(3):193-197

22. Karlinski M, Kobayashi A, Czlonkowska A, Mikulik R, Vaclavik D, Brozman M, Svigelj V, Csiba L, Fekete K, Korv J, Demarin V, Vilionskis A, Jatuzis D, Krespi Y, Ahmed N, Wahlgren N, Safe Implementation of Treatments in Stroke-Eastern Europe I (2014) 
Role of preexisting disability in patients treated with intravenous thrombolysis for ischemic stroke. Stroke 45(3):770-775. https:// doi.org/10.1161/STROKEAHA.113.003744

23. Koennecke H-C, Belz W, Berfelde D, Endres M, Fitzek S, Hamilton F, Kreitsch P, Mackert B-M, Nabavi DG, Nolte CH, Pöhls W, Schmehl I, Schmitz B, von Brevern M, Walter G, Heuschmann PU (2011) Factors influencing in-hospital mortality and morbidity in patients treated on a stroke unit. Neurology 77(10):965-972. https ://doi.org/10.1212/WNL.0b013e31822dc795

24. Knoflach M, Matosevic B, Rücker M, Furtner M, Mair A, Wille G, Zangerle A, Werner P, Ferrari J, Schmidauer C, Seyfang L, Kiechl S, Willeit J (2012) Functional recovery after ischemic stroke-a matter of age data from the Austrian Stroke Unit Registry. Neurology 78(4):279-285. https://doi.org/10.1212/WNL.0b013e3182 4367ab

25. Luedi R, Hsieh K, Slezak A, El-Koussy M, Fischer U, Heldner MR, Meisterernst J, Mono M-L, Zubler C, Mordasini P, Ozdoba C, Mattle HP, Schroth G, Gralla J, Arnold M, Jung S (2014) Age dependency of safety and outcome of endovascular therapy for acute stroke. J Neurol 261(8):1622-1627. https://doi.org/10.1007/ s00415-014-7401-0

26. Rost NS, Bottle A, Lee J-M, Randall M, Middleton S, Shaw L, Thijs V, Rinkel GJE, Hemmen TM, Gc GCS (2016) Stroke severity is a crucial predictor of outcome: an international prospective validation study. J Am Heart Assoc 5(1):e002433. https://doi. org/10.1161/JAHA.115.002433

27. Jiang S, Fei A, Peng Y, Zhang J, Lu Y-r, Wang H-r, Chen M, Pan $S$ (2015) Predictors of outcome and hemorrhage in patients undergoing endovascular therapy with solitaire stent for acute ischemic stroke. PLoS ONE 10(12):e0144452. https://doi.org/10.1371/ journal.pone.0144452

28. Finlayson O, Kapral M, Hall R, Asllani E, Selchen D, Saposnik G (2011) Risk factors, inpatient care, and outcomes of pneumonia after ischemic stroke. Neurology 77(14):1338-1345. https://doi. org/10.1212/WNL.0b013e31823152b1

29. Anderson C (1994) Baseline measures and outcome predictions. Neuroepidemiology 13(6):283-289. https://doi. org/10.1159/000110392

30. Harwood RH, Gompertz P, Pound P, Ebrahim S (1997) Determinants of handicap 1 and 3 years after a stroke. Disabil Rehabil 19(5):205-211. https://doi.org/10.3109/09638289709166528

31. Bamford J, Dennis M, Sandercock P, Burn J, Warlow C (1990) The frequency, causes and timing of death within 30 days of a first stroke: the Oxfordshire Community Stroke Project. J Neurol Neurosurg Psychiatry 53(10):824-829. https://doi.org/10.1136/ jnnp.53.10.824

32. Leker RR, Gavriliuc P, Yaghmour NE, Gomori JM, Cohen JE (2018) Increased risk for unfavorable outcome in patients with pre-existing disability undergoing endovascular therapy. J Stroke Cerebrovasc Dis 27(1):92-96. https://doi.org/10.1016/j.jstrokecer ebrovasdis.2017.08.007

33. Bath PM, Lees KR, Schellinger PD, Altman H, Bland M, Hogg C, Howard G, Saver JL, European Stroke Organisation Outcomes Working G (2012) Statistical analysis of the primary outcome in acute stroke trials. Stroke 43(4):1171-1178. https://doi. org/10.1161/STROKEAHA.111.641456

34. Campbell BC, Mitchell PJ, Kleinig TJ, Dewey HM, Churilov L, Yassi N, Yan B, Dowling RJ, Parsons MW, Oxley TJ, Wu TY, Brooks M, Simpson MA, Miteff F, Levi CR, Krause M, Harrington TJ, Faulder KC, Steinfort BS, Priglinger M, Ang T, Scroop R, Barber PA, McGuinness B, Wijeratne T, Phan TG, Chong W, Chandra RV, Bladin CF, Badve M, Rice H, de Villiers L, Ma H, Desmond PM, Donnan GA, Davis SM, Investigators E-I (2015) Endovascular therapy for ischemic stroke with perfusionimaging selection. N Engl J Med 372(11):1009-1018. https://doi. org/10.1056/NEJMoa1414792
35. Saver JL, Goyal M, Bonafe A, Diener H-C, Levy EI, Pereira VM, Albers GW, Cognard C, Cohen DJ, Hacke W, Jansen O, Jovin TG, Mattle HP, Nogueira RG, Siddiqui AH, Yavagal DR, Baxter BW, Devlin TG, Lopes DK, Reddy VK, de du Mesnil Rochemont R, Singer OC, Jahan R (2015) Stent-retriever thrombectomy after Intravenous t-PA vs t-PA alone in stroke. N Engl J Med 372(24):2285-2295. https://doi.org/10.1056/NEJMoa1415061

36. Jovin TG, Chamorro A, Cobo E, de Miquel MA, Molina CA, Rovira A, San Román L, Serena J, Abilleira S, Ribó M, Millán M, Urra X, Cardona P, López-Cancio E, Tomasello A, Castaño C, Blasco J, Aja L, Dorado L, Quesada H, Rubiera M, HernandezPérez M, Goyal M, Demchuk AM, von Kummer R, Gallofré M, Dávalos A (2015) Thrombectomy within 8 hours after symptom onset in ischemic stroke. N Engl J Med 372(24):2296-2306. https ://doi.org/10.1056/NEJMoa1503780

37. Goyal M, Demchuk AM, Menon BK, Eesa M, Rempel JL, Thornton J, Roy D, Jovin TG, Willinsky RA, Sapkota BL, Dowlatshahi D, Frei DF, Kamal NR, Montanera WJ, Poppe AY, Ryckborst KJ, Silver FL, Shuaib A, Tampieri D, Williams D, Bang OY, Baxter BW, Burns PA, Choe H, Heo JH, Holmstedt CA, Jankowitz B, Kelly M, Linares G, Mandzia JL, Shankar J, Sohn SI, Swartz RH, Barber PA, Coutts SB, Smith EE, Morrish WF, Weill A, Subramaniam S, Mitha AP, Wong JH, Lowerison MW, Sajobi TT, Hill MD, Investigators ET (2015) Randomized assessment of rapid endovascular treatment of ischemic stroke. N Engl J Med 372(11):1019-1030. https://doi.org/10.1056/NEJMoa1414905

38. Tan C-C, Wang H-F, Ji J-L, Tan M-S, Tan L, Yu J-T (2017) Endovascular treatment versus intravenous thrombolysis for acute ischemic stroke: a quantitative review and meta-analysis of 21 randomized trials. Mol Neurobiol 54(2):1369-1378. https://doi. org/10.1007/s12035-016-9738-0

39. Nogueira RG, Gupta R, Jovin TG, Levy EI, Liebeskind DS, Zaidat OO, Rai A, Hirsch JA, Hsu DP, Rymer MM, Tayal AH, Lin R, Natarajan SK, Nanda A, Tian M, Hao Q, Kalia JS, Chen M, Abou-Chebl A, Nguyen TN, Yoo AJ (2015) Predictors and clinical relevance of hemorrhagic transformation after endovascular therapy for anterior circulation large vessel occlusion strokes: a multicenter retrospective analysis of 1122 patients. J NeuroInterv Surg 7(1):16. https://doi.org/10.1136/neurintsurg-2013-010743

40. Hao Y, Yang D, Wang H, Zi W, Zhang M, Geng Y, Zhou Z, Wang W, Xu H, Tian X, Lv P, Liu Y, Xiong Y, Liu X, Xu G, Null N, Liu C, Shi Z, Zhang J, Lin H, Lin M, Hu Z, Deng X, Wan Y, Zhang J, Shi Z, Qu M, Huang X, Quan T, Guan S, Chen L, Li X, Wang S, Yang S, Liu W, Wei D, Wang Z, Liu X, Guo F, Yang S, Zheng D, Wu X, Zeng Y, Tu M, Jin P, Liu Y, Li H, Fang J, Xiao G (2017) Predictors for symptomatic intracranial hemorrhage after endovascular treatment of acute ischemic stroke. Stroke 48(5):1203-1209. https://doi.org/10.1161/STROKEAHA.116.016368

41. Wang DT, Churilov L, Dowling R, Mitchell P, Yan B (2015) Successful recanalization post endovascular therapy is associated with a decreased risk of intracranial haemorrhage: a retrospective study. BMC Neurol 15(1):185. https://doi.org/10.1186/s1288 3-015-0442-X

42. Kaesmacher J, Kaesmacher M, Maegerlein C, Zimmer C, Gersing AS, Wunderlich S, Friedrich B, Boeckh-Behrens T, Kleine JF (2017) Hemorrhagic transformations after thrombectomy: risk factors and clinical relevance. Cerebrovasc Dis 43(5-6):294-304. https://doi.org/10.1159/000460265

43. Zhu F, Labreuche J, Haussen Diogo C, Piotin M, Steglich-Arnholm H, Taschner C, Papanagiotou P, Lapergue B, Dorn F, Cognard C, Killer M, Psychogios Marios N, Spiotta A, Mazighi M, Bracard S, Turjman F, Richard S, GoryNull BN (2019) Hemorrhagic transformation after thrombectomy for tandem occlusions. Stroke 50(2):516-519. https://doi.org/10.1161/STROK EAHA.118.023689 
44. Jansen IGH, Mulder M, Goldhoorn RB, Investigators MCR (2018) Endovascular treatment for acute ischaemic stroke in routine clinical practice: prospective, observational cohort study (MR CLEAN Registry). BMJ 360:k949. https://doi.org/10.1136/bmj.k949

45. Fearon P, McArthur KS, Garrity K, Graham LJ, McGroarty G, Vincent S, Quinn TJ (2012) Prestroke modified rankin stroke scale has moderate interobserver reliability and validity in an acute stroke setting. Stroke 43(12):3184-3188. https://doi.org/10.1161/ STROKEAHA.112.670422
46. Prakapenia A, Gruener C, Winzer S, Barlinn J, Gerber J, Pallesen L-P, Siepmann T, Moustafa H, Reichmann H, Linn J, Puetz V, Barlinn K (2019) Misjudgment of pre-stroke functional status contradicts beneficial outcomes after endovascular therapy for large vessel occlusion. J Neurol. https://doi.org/10.1007/s0041 5-019-09384-z 